\title{
A Conservação da Ararinha-azul, Cyanopsitta spixii (Wagler, 1832): Desafios e Conquistas
}

\author{
Camile Lugarini ${ }^{1}$, Ugo Eichler Vercillo ${ }^{2}$, Cromwell Purchase ${ }^{3}$, Ryan Watson ${ }^{4}$, Natasha Schischakin ${ }^{4}$
}

Recebido em 11/08/2020 - Aceito em 03/01/2021

1 Centro Nacional de Pesquisa e Conservação de Aves Silvestres/CEMAVE, Instituto Chico Mendes de Conservação da Biodiversidade/ICMBio,
Florianópolis/SC, Brasil. CEP: 88.053-700. < camile.lugarini@icmbio.gov.br>.
2 Instituto Chico Mendes de Conservação da Biodiversidade/ICMBio, Brasília/DF, Brasil. CEP: 70.670-350. <ugo.vercillo@icmbio.gov.br>.
${ }_{3}$ Association for the Conservation of Threatened Parrots/ACTP, Curaçá/BA, Brasil. CEP: 48.930-000. <dr.cromwell.purchase@act-parrots.eu>.
4 Autônomo.

RESUMO - A ararinha-azul (Cyanopsitta spixii) é o único representante do seu gênero e hoje é considerada provavelmente extinta na natureza. $\mathrm{O}$ manejo ex situ é prioridade na estratégia de conservação desde o início da década de 90, sendo um exemplo de parceria público-privada de sucesso. Em 2017, finalmente, a população cativa alcançou a estabilidade com 152 indivíduos, possibilitando planejar as ações de reintrodução. Além disso, duas unidades de conservação foram criadas para propiciar a recuperação da espécie no ambiente natural, e, em 2020, 52 ararinhas-azuis foram repatriadas para um Centro de Reprodução e Reintrodução no interior do Refúgio de Vida Silvestre da Ararinha Azul. Aproximadamente 20 ararinhas-azuis estão em adaptação para o início da reintrodução e restabelecimento da população na área de distribuição histórica. Estamos perto de devolver a espécie para o seu ambiente natural, de onde nunca deveria ter sido extirpada.

Palavras-chave: Ameaçada de extinção; extinta na natureza; ex situ; manejo populacional; plano de ação nacional.

\section{The Conservation of the Spix's Macaw, Cyanopsitta spixii (Wagler, 1832): Challenges and Achievements}

ABSTRACT - The Spix's Macaw (Cyanopsitta spixii) is the only representative of its genus and is currently considered probably extinct in the wild. Ex situ management is the priority of the conservation strategy since 90's. Finally, in 2017, the captive population of Spix's Macaws reached 152 individuals, making possible to plan reintroduction actions. Moreover, two protected areas were created to recover the species in the natural environment, and, in 2020, 52 Spix's Macaws were repatriated for the Reproduction and Reintroduction Center inside the Spix's Macaw Wildlife Refuge. Approximately 20 macaws are in preparation for the reintroduction and restoration of the population in their historical range. We are close to returning this species to its natural environment, where they should have never been removed.

Keywords: Threatened; extinct in the wild; ex situ; population management; national action plan.

\section{La Conservación del Guacamayo de Spix, Cyanopsitta spixii (Wagler, 1832): Desafíos y Logros}

RESUMEN - El guacamayo azul (Cyanopsitta spixii) es el único representante de su género y actualmente es considerado probablemente extinto en estado silvestre. El manejo ex situ ha sido una prioridad en la estrategia de conservación desde los principios de la década de 1990, siendo un ejemplo de una asociación público-privada exitosa. En 2017, finalmente, la población cautiva alcanzó la estabilidad con 152 individuos, lo que permitió planificar acciones de reintroducción. Además, se crearon dos unidades de conservación para promover la recuperación de la especie en el medio natural, y en 2020 se repatriaron 52 guacamayos azules a un Centro de Reproducción y Reintroducción dentro del Refugio de Vida Silvestre Ararinha Azul. Aproximadamente 20 guacamayos 
azules están siendo adaptados para el inicio de la reintroducción y restauración de la población en el área de distribución histórica. Estamos cerca de devolver la especie a su medio natural, de donde nunca debió haber sido desarraigada.

Palabras clave: Amenazado de extinción; extinto en la naturaleza; ex situ; manejo de población; plan de acción nacional.

\section{Introdução}

Os impactos antrópicos sobre as paisagens naturais representam a principal causa da perda da biodiversidade e do declínio populacional de diversas espécies, incluindo os Psittaciformes (Olah et al., 2016; Berkunsky et al., 2017; Vergara-Tabares et al., 2020). Essa Ordem abriga papagaios, araras, periquitos $e$ cacatuas, dividida em quatro famílias e 387 espécies (Billerman, 2020). Quase um terço dessas espécies está ameaçado de extinção e $56 \%$ delas encontra-se em declínio populacional (Olah et al., 2016). Os representantes azuis deste grupo estão particularmente ameaçados, como a possivelmente extinta Anodorhynchus glaucus (Butchart et al., 2018); a extinta na natureza e que necessita de reintrodução (ararinha-azul, Cyanopsitta spixii, Butchart et al., 2018); a em perigo de extinção arara-azul-de-lear, A. leari (MMA, 2014a; BirdLife International, 2019a), que necessita de manejo populacional intenso em pelo menos uma de suas populações (Lugarini et al., 2012); e a vulnerável arara-azul-grande, A. hyacinthinus (BirdLife International, 2016).

A conversão de habitat tropicais e subtropicais representa a principal ameaça para esse grupo (Olah et al., 2016; Vergara-Tabares et al., 2020). É uma consequência dos diferentes usos do solo como agricultura, pecuária, desmatamento e extração de madeira (Olah et al., 2016), com grande relevância no Neotrópico (Berkunsky et al., 2017). A perda de habitat age sinergicamente com outras ameaças como captura e caça (Berkunsky et al., 2017), assim como espécies invasoras, poluição e perseguição (Butchart et al., 2006; Berkunsky et al., 2017). Como consequência, as pequenas populações podem ficar isoladas e se tornarem altamente suscetíveis a ameaças estocásticas, levando a um ciclo de declínio populacional e extinção (chamado de "vórtice de extinção") (IUCN/SSC, 2014).

As ações de conservação, que incluem o manejo e a proteção do habitat, o controle de espécies invasoras e um manejo populacional intensivo, são as mais efetivas para garantir a viabilidade de pequenas populações, restritas $e$ isoladas (Butchart et al., 2006). Essas ações são organizadas em programas ou planos para a conservação das espécies ameaçadas. No Brasil, os Planos de Ação Nacionais para Conservação de Espécies Ameaçadas de Extinção (PAN) estabelecem ações in situ e ex situ para conservação e recuperação das espécies em risco de extinção (MMA, 2014b). São considerados as estratégias oficiais para a conservação de espécies ameaçadas (MMA, 2018).

Estima-se que pelo menos 16 espécies de aves criticamente em perigo em nível global tiveram suas populações resguardadas entre 1994-2004, em decorrência de programas de conservação aplicados por agências governamentais e não governamentais (Butchart et al., 2006). Muitas delas dependentes da conservação ex situ para o crescimento populacional e posterior reintrodução. Citamos aqui três exemplos emblemáticos de conservação de espécies de aves com manejo intensivo de sucesso. O mais conhecido é do condor-da-Califórnia (Gymnogyps californianus), com grande esforço de manejo populacional in situ para possibilitar a recuperação da espécie em ambiente natural. Em 2019 foi comemorada a saída do ninho do milésimo filhote no Zion National Park e o primeiro por incubação natural desde o início do manejo populacional na década de 90 (NPS, 2019). Um bom exemplo envolvendo psitacídeo é o do periquito das ilhas Mauritius (Psittacula eques). Em 1994 havia cinco pares em cativeiro, três deles não reprodutivos e, em fevereiro de 2005, havia 55 pares ou aproximadamente 300 aves na natureza. Isso foi conseguido em decorrência de ações de conservação, que incluíram a reprodução em cativeiro e o manejo do habitat. Por último, citamos o falcão-de-Mauritius (Falco punctatus), que em 1994 tinha uma população de quatro indivíduos na natureza, e em 2006 apresentava de 500 a 800 indivíduos. A estratégia de conservação contou com um programa de cativeiro e reintrodução, alimentação suplementar, colocação de caixas- 
ninho, monitoramento de ninhos e controle de predadores (Safford \& Jones, 1998).

No Brasil, duas espécies de aves são estritamente dependentes da conservação ex situ e da reintrodução: o mutum-de-Alagoas (Pauxi mitu) e a ararinha-azul (Cyanopsitta spixii), visto estarem extintas na natureza (MMA, 2014a; BirdLife International, 2018, 2019b; Butchart et al., 2018).

O pressuposto do manejo ex situ para a conservação é possibilitar a viabilidade das populações, espécies ou ecossistema que ocupam. $\mathrm{O}$ objetivo pode incluir o fornecimento de indivíduos para reintrodução, para o resgate genético, como seguro (backup) contra extinção e para permitir a educação para sustentabilidade ambiental, pesquisa e treinamento para a conservação. Nem todas as estratégias de conservação de espécies exigem um componente ex situ. Em alguns casos, o manejo ex situ é a parte principal da estratégia de conservação, como é para a ararinha-azul. Em outras é de importância secundária, apoiando outras intervenções (IUCN/ SSC, 2014), como para a arara-azul-de-lear (Lugarini et al., 2012).

Se por um lado a manutenção de psitacídeos como animais de estimação é uma prática muito difundida afetando muitas espécies (Forshaw, 2010). Por outro, existe uma longa história de convivência dos psitacídeos com a sociedade humana, consequência de sua aparência carismática e inteligência. Isso confere a possibilidade de utilizá-los como espécies bandeira para conservar regióes degradadas (Fleishman et al., 2000; Snyder et al., 2000). Esse é o caso da ararinha-azul, uma espécie que atrai a atenção de todos, especialmente após o lançamento dos longas-metragens Rio e Rio 2, nos anos 2011 e 2014. É também uma das espécies mais emblemáticas da perda da biodiversidade brasileira (Brettas \& Silveira, 2015).

$\mathrm{O}$ presente artigo discute, portanto, $\mathrm{O}$ processo histórico e gargalos relacionados ao manejo ex situ da ararinha-azul, além de avaliar o avanço atingido até julho de 2020. A documentação a respeito da ararinha-azul foi levantada incluindo os processos institucionais que tratavam do Programa de Cativeiro da espécie (ICMBio, 2013), relatórios do Livro Genealógico (Watson, 2011; Purchase, 2019) e Plano de Ação Nacional (ICMBio, 2012a, 2016a, 2019), além da complementação de artigos obtidos na internet nas plataformas google scholar, bioone e pubmed, utilizando a palavra-chave Cyanopsitta spixii. Também se utilizou informações do site: www. bluemacaws.org/en-gb/articles/the-spixs-macaw. Por último, foram consideradas as publicações de Schischakin (1999, 2003), Juniper (2002), Soye \& Barros (2007) e Barros et al. (2012).

\section{As iniciativas de conservação da ararinha- azul}

Apesar de ter sido descoberta em 1819, e descrita em 1832, a área exata da ocorrência da ararinha-azul permaneceu indefinida até 1986, quando três indivíduos foram avistados no riacho da Melancia, no município de Curaçá (Roth 1990a, 1990b), no estado da Bahia. Pela sua beleza e raridade, foi vítima de colecionadores tanto brasileiros quanto internacionais de aves silvestres antes mesmo da descoberta de sua origem pela ciência. A captura data do início do século XX e se intensificou nas décadas de 60 a 80, levando a um profundo declínio populacional (Juniper, 2002). A espécie foi primeiramente considerada vulnerável (King, 1978), em perigo em 1988, criticamente em perigo de 1994 a 2018 e extinta na natureza em 2019 (BirdLife International, 2019b). O seu estado de conservação parece ter sido historicamente superestimado (Schischakin, 2003), e em julho de 1990, havia apenas uma única ave remanescente, proveniente de uma população restrita, provavelmente de 30 pares. Essa estimativa é baseada em relato de moradores da região de ocorrência histórica e antigos coletores (Juniper \& Yamashita, 1990).

Foi a partir do registro do último indivíduo na natureza, em 1990, que o Instituto Brasileiro de Meio Ambiente e Recursos Naturais Renováveis (IBAMA) criou o Comitê Permanente para a Recuperação da Ararinha-azul (CPRAA) (Barros et al., 2012). No ano seguinte se iniciaram os trabalhos de campo para monitorar o último macho selvagem, o qual desapareceu em outubro de 2000, desmobilizando as parcerias estabelecidas até então para a sua conservação (Juniper, 2002). Coube ao Instituto Chico Mendes de Conservação da Biodiversidade (ICMBio) integrar os grupos existentes por meio do PAN Ararinhaazul (ICMBio, 2012a), que estabeleceu a estratégia de conservação para a espécie (MMA, 2014b). O PAN, em seu primeiro ciclo, detinha ações 
planejadas com objetivo de aumento da população manejada em cativeiro. Além disso, contavase com ações de recuperação e conservação do habitat na área de ocorrência histórica da espécie, visando o início de reintroduções até 2021 (ICMBio, 2016a). Para tanto, os esforços de conservação participativa incluíram instituições que mantinham e/ou reproduziam a espécie (mantenedores), instituições de ensino e pesquisa, outras instituições públicas e organizações não governamentais (ONGs). O ICMBio possibilitou o trabalho conjunto, o comprometimento dos envolvidos, a articulação entre instituições, a captação de recurso junto a empresas, a capacitação e a adesão dos mantenedores em prol da conservação da espécie.

Além disso, por meio do Programa Carteira Fauna, a Vale S.A. (mineradora multinacional brasileira) e o Fundo Brasileiro para a Biodiversidade (Funbio) celebraram, em 2012, o Contrato de Patrocínio para a implementação do Projeto Ararinha na Natureza. O Projeto que vigorou até junho de 2019, implementou parte do PAN Ararinha-azul, com aporte de recursos no Programa Carteira Fauna de $\mathrm{R} \$$ 4.121.972,62. Soma-se, ainda, o montante de recurso desembolsado pela Al Wabra Wildlife Preservation (AWWP), Association for the Conservation of Threatened Parrots (ACTP), Nest, Fundação Lymington e Fazenda Cachoeira para a manutenção e reprodução em cativeiro. As atividades desenvolvidas durante a vigência do Projeto Ararinha na Natureza culminaram com a criação de duas unidades de conservação (UCs), em 05 de junho de 2018: o Refúgio de Vida Silvestre (RVS) e a Área de Proteção Ambiental (APA) da Ararinha Azul. Os objetivos das UCs criadas (Brasil, 2018) convergem com a estratégia de conservação da ararinha-azul, definidas no PAN da espécie (ICMBio, 2016a).

Ademais, ressalta-se o esforço de conservação de áreas historicamente importantes para a ararinha-azul, como a aquisição da Fazenda Gangorra de 400ha pela Fundação Lymington, em 2007 (Barros et al., 2012), e da Fazenda Concórdia, de 2380ha pela AWWP, em 2008 (Hammer \& Watson, 2012). A Fazenda Concórdia foi inteiramente cercada e excluída da pecuária, em 2013, para recuperação da vegetação remanescente. Por último, houve a aquisição da Fazenda Ararinha-azul em 2018, entre a Fazenda Gangorra e Concórdia, onde foi construído o Centro de Reprodução e Reintrodução da Ararinha-azul (2019-2020). Todas essas fazendas estão localizadas no interior da unidade de conservação de proteção integral, o RVS da Ararinha Azul.

Em 2017 foi concluído o primeiro ciclo do PAN. O segundo ciclo (2019-2024) tem como objetivo geral "Realizar a reintrodução de ararinhas-azuis em sua área de ocorrência original até 2024, buscando seu aumento populacional contínuo e conservando habitat com envolvimento comunitário em práticas sustentáveis" (ICMBio, 2019).

\section{Histórico do manejo ex situ da ararinha-azul}

Por não haver população conhecida da ararinha-azul em vida livre, o manejo ex situ da espécie visa restaurar a população selvagem (reintrodução) (IUCN/SSC, 2013). O primeiro esforço para a criação de um programa de manejo ex situ para a conservação da espécie foi realizado em 1987, pelo Loro Parque, em Tenerife. Nessa época se contava com aproximadamente 20 animais em alguns colecionadores privados internacionais e nos estados do Rio de Janeiro e de São Paulo, no Brasil. O segundo esforço empreendido foi em 1988, no Segundo Encontro Internacional do Grupo de Especialistas em Psitacídeos do Conselho Internacional de Preservação de Aves (International CouncilforBirdPreservation-ICBP), da União Internacional para a Conservação da Natureza (acrônimo IUCN do inglês International Union for Conservation of Nature), em Curitiba, no estado do Paraná. Não houve a concepção de um programa de manejo, especialmente, devido a divergências quanto à propriedade dos animais cativos (Schischakin, 2003).

Somente em 1989, o governo brasileiro criou o Grupo de Trabalho Temporário para a Recuperação da Ararinha-azul, para o estabelecimento de um programa de manejo oficial em cativeiro, com representantes de mantenedores e ornitólogos de campo (Schischakin, 2003). No ano seguinte, o grupo temporário obteve caráter permanente com a criação do CPRAA (Barros et al., 2012).

Nessa época se contava com apenas 11 animais em cativeiro (Schischakin, 1999), sendo seis no Brasil (Barros et al., 2012). A população em cativeiro enfrentou um declínio considerável nos 
anos que antecederam a formação da população manejada oficialmente, com a perda de indivíduos antes da sua reprodução. O pareamento no Brasil era prejudicado pela falta de informações a respeito do sexo dos indivíduos. Não há dimorfismo sexual externo para a espécie e não se dispunha de técnicos brasileiros treinados para promover a sexagem necessária (Schischakin, 2003).

Portanto, havia um risco eminente da perda da espécie e era necessário incluir mais exemplares na população manejada em cativeiro, o que foi o foco da estratégia estabelecida naquela época (Schischakin, 2003). O IBAMA, então, em caráter excepcional, decidiu não confiscar as ararinhas-azuis que estivessem submetidas ao programa de manejo da espécie (IBAMA, 1990). Essa anistia, bastante controversa na época, não surtiu efeito, visto não haver aderência de aves criadas ilegalmente no Brasil e não ter efeito para mantenedores fora do Brasil, considerando a soberania de cada país. A anistia não era sinônimo do retorno da propriedade dos animais ao Brasil e os mantenedores legalizados no exterior mantiveram a propriedade de suas aves. Enquanto isso, os grupos dos conservacionistas clamavam o retorno de todas as aves ao Brasil e domínio total sobre o plantel, o que não era aceito por grande parte dos mantenedores (Schischakin, 2003).

A reprodução em cativeiro parece ter sido conseguida por alguns mantenedores particulares no Brasil, os quais parecem ter abastecido a população internacional. Alvaro Rossman Carvalhães, em Santos, no estado de São Paulo, foi o que obteve maior sucesso nas décadas de 50 a 70, produzindo aproximadamente 25 filhotes (Soye \& Barros, 2007). No exterior, Josef Hämmerli, na Suíça, foi o primeiro mantenedor a produzir ararinhas, em 1984. No entanto, foi Antonio de Dios, que teve os melhores resultados na Birds International Incorporated (BII), nas Filipinas, produzindo 39 filhotes, de 1982 a 2001. Esta coleção alcançou a segunda geração em cativeiro (F2), um verdadeiro avanço para a sobrevivência desta espécie. Tanto de Dios quanto Hämmerli continuaram sua criação bem-sucedida $e$ promoveram o crescimento populacional da espécie nas décadas de 80 e 90. Em 1993, assinaram o Termo de Responsabilidade para ingressar no então criado CPRAA, juntamente com a Fundação Loro Parque (FLP), Criadouro Chaparral e Criadouro Arco-Íris. A prioridade naquele momento era o aumento populacional o mais rápido possível, pois essa era a única maneira de garantir uma população cativa estável e a única chance de sobrevivência da espécie (Schischakin, 2003).

Foi então, com base nos dados demográficos, discutido o pareamento a partir da medição do parentesco médio (mean kinship - MK). Esse é um valor numérico que descreve o quão próximo um indivíduo está relacionado a outro membro da população. Animais com parentesco médio baixo são geneticamente importantes, mas infelizmente, em função da razão sexual, alguns dos machos mais jovens não puderam ser pareados (Schischakin, 2003). Para proporcionar o pareamento de aves fundadoras (aves provenientes de vida livre F0) existentes em mantenedores brasileiros e em instituições estrangeiras, a atual Fundação Parque Zoológico de São Paulo (FPZSP) encaminhou duas ararinhas-azuis para o Loro Parque, no interesse da conservação da espécie.

Ao mesmo tempo, de Dios encaminhou duas ararinhas-azuis como doação à FPZSP, além de encaminhar uma ararinha-azul produzida na BII como doação da propriedade ao Brasil para ser pareada com o macho, que ficou sozinho no Criadouro Chaparral após a soltura da fundadora em 1995. Essa soltura foi realizada para propiciar o pareamento do único macho registrado em vida livre, mas não se obteve sucesso (Barros et al., 2012).

Em 1999, a população em cativeiro dobrou em relação àquela de 1993, chegando a 60 indivíduos (54 nascidos em cativeiro de acordo com Schischakin, 1999). Isso pelo sucesso dos dois mantenedores particulares sob responsabilidade da BII e de Hämmerli. A FLP havia conseguido a reprodução de um casal fundador em 1992, mas encontrou dificuldades na reprodução dos animais provindos no Brasil (LPF, 1999). No Brasil, somente o Criadouro Chaparral, em Recife, registrou nascimento de duas ararinhas-azuis após o estabelecimento do CPRAA, em 2000 (Schischakin, 2003).

No final da década de 90 o programa de manejo enfrentava diversos conflitos entre mantenedores, além da necessidade de dividir o plantel para evitar que catástrofes que pudessem comprometer a população em cativeiro. Hämmerli, então, vendeu 15 das 20 ararinhas-azuis para o suíço Roland Messer, que continuou auxiliando o manejo em cativeiro da espécie. Enquanto outros 
dois colecionadores desconhecidos declinaram do convite de ingressar no CPRAA. Posteriormente, de Dios encaminhou dois casais para a AWWP, no Catar, sem a anuência prévia do Comitê. Por último, a morte de fundadores fez com que a população total reduzisse pela primeira vez na história do programa de manejo ex situ. As necessidades de pareamento foram discutidas em uma reunião em Brasília, em 2001. A propriedade das aves entrou novamente em pauta e houve rejeição na aceitação da AWWP no CPRAA, o que causou o distanciamento de Messer e de Dios. Definiu-se, então, por uma total reestruturação do Comitê, o qual, até então, tinha um caráter deliberativo (Schischakin, 2003).

O IBAMA encaminhou no início de 2002 uma proposta de restruturação, fundada no princípio de que o governo brasileiro deveria ter soberania sobre todas as aves e controle total dos espécimes, a qual foi rechaçada pelos mantenedores internacionais. Das 60 aves existentes, somente oito eram de propriedade brasileira. O plantel de propriedade brasileira apresentava, no entanto, crescimento negativo entre 1989 e 2001, enquanto os de propriedade privada apresentavam crescimento de $750 \%$ no mesmo período. Foi, então, que um Memorando de Entendimento resultante do $1^{\circ}$ Encontro de Proprietários de Ararinhas-azuis (chamado de Acordo de Genebra) foi instituído em setembro do mesmo ano, para coordenar a iniciativa pelos mantenedores privados, sem a participação do governo brasileiro e dos zoológicos, marcando o distanciamento das instituições mantenedoras $e$ o governo brasileiro. Neste momento, propostas de reintrodução de cinco aves do programa de manejo em cativeiro discutidas anteriormente foram deixadas de lado, visto o desaparecimento do último indivíduo em vida livre e a necessidade de fortalecer a população em cativeiro (Schischakin, 2003).

Até 2004, toda a população de 25 aves foi transferida da BII, nas Filipinas, para a AWWP, no Catar, completando 29 ararinhas-azuis no total. Dezenove eram de segunda geração e muito endogâmicas, ou seja, aparentadas entre si, sendo possível reproduzir apenas nove delas. Quanto à população suíça recebida do senhor Messer pela AWWP, por um tempo, as ararinhas-azuis foram manejadas em duas instalações: no Catar, e no mantenedor de Roland Messer, na Suíça. Em 2005, as 12 ararinhas restantes (total 15) foram encaminhadas à AWWP, formando a maior coleção em cativeiro (43 de aproximadamente 68 aves, de acordo com Soye \& Barros, 2007). Essa população obteve bons resultados de produção de filhotes $(\mathrm{n}=14)$ nos anos de 2005, 2006 e 2007. Por último, em 2005, a ACTP adquiriu as últimas três aves de Messer (Hammer \& Watson, 2012), com o compromisso de colaborar com a conservação da espécie (Barros et al., 2012).

Somente em 2005 foi estabelecido o Grupo de Trabalho para a Recuperação da Ararinhaazul, visando incluir o maior número de aves no programa de reprodução da espécie (Barros et al., 2012). A AWWP aceitou, então, o convite do IBAMA para ingressar oficialmente no Grupo e todas as suas ararinhas-azuis foram incluídas no Livro Genealógico Internacional (Watson, 2011). Acordos de empréstimo e manejo foram, então, assinados entre a ACTP e FLP para possibilitar transferências indicadas pelos consultores.

Em 2011, existiam 87 ararinhas-azuis no mundo, sendo que 75 delas participavam do manejo internacional, com $73,3 \% \quad(n=55)$ da população presente na AWWP (Hammer \& Watson, 2012). Posteriormente à publicação da Instrução Normativa ICMBio $n^{\circ}$ 22/2012 (ICMBio, 2012b), que instituiu os Programas de Cativeiro para espécies ameaçadas, houve um esforço para que os mantenedores de ararinhasazuis assinassem o termo de adesão ao Programa de Cativeiro da Ararinha-azul. A FLP e a ACTP apresentaram sucesso de reprodução a partir de 2004, mas foi na AWWP que se conseguiu os melhores resultados (Barros et al., 2012). Apesar disso, os indivíduos mantidos pela ACTP eram geneticamente diferenciados da população da AWWP e do Brasil. Portanto, havia a necessidade de realizar os pareamentos e transferências recomendadas pelo consultor genealógico anos antes, a qual foi considerada prioritária para manter a diversidade genética em torno de $75 \%$. Nesse momento, a FLP descontinuou suas atividades no programa, possibilitou a repatriação das ararinhas-azuis mantidas até então por eles e encaminhou dois indivíduos para a ACTP, inclusive um macho fundador. Além disso, as quatro aves mantidas na FPZSP foram transportadas para um novo mantenedor no Brasil, o criadouro conservacionista Nest, em Avaré, no interior de São Paulo, com o intuito de formação de um centro reprodutor no Brasil (Barros et al., 2012). 
Até 2012 o Programa registrava nascimento de um a dez filhotes por ano. As transferências de ararinhas-azuis foram impulsionadas a partir desse ano, possibilitando um intercâmbio genético considerável entre os mantenedores, as quais tiveram um papel importante nos resultados reprodutivos obtidos posteriormente. Para reduzir os problemas genético e hormonal que afetavam negativamente a reprodução (Hammer \& Watson, 2012), em 2013, a AWWP assinou um contrato com a Parrots Reproduction Consulting e começou a realizar a reprodução assistida das ararinhas-azuis, gerando dois filhotes por meio da inseminação artificial (Purchase, 2019).

Os resultados de nascimento de filhotes a partir da inseminação artificial foram novamente obtidos novamente em 2014. A produção excepcional de filhotes possibilitou a formação de casais jovens provenientes de todos os mantenedores posteriormente em território brasileiro (Purchase, 2019). Todos os mantenedores do Programa de Cativeiro (AWWP, ACTP e Nest no Brasil) produziram filhotes no mesmo ano pela primeira vez. Além disso, o mantenedor Nest, conseguiu a reprodução depois de 14 anos sem sucesso no solo brasileiro e, pela primeira vez, produziu os dois primeiros filhotes por incubação natural.
Finalmente, em 2015, a AWWP aderiu oficialmente ao Programa de Cativeiro da espécie gerenciado pelo ICMBio e juntamente com a ACTP produziu um total de 20 filhotes; em 2016, 23 filhotes; e em 2017, 26 filhotes (Figura 1). Logo, os primeiros anos do PAN foram marcados por um grande sucesso reprodutivo da ararinhaazul, especialmente na AWWP, o que fez com que o plantel dobrasse em número de indivíduos (Purchase, 2019).

A meta relacionada ao objetivo 1 do PAN (população de cativeiro adequadamente manejada, com aumento de $10 \%$ ao ano, visando um mínimo de 150 indivíduos) foi atingida, devido, especialmente, à combinação de melhores pareamentos e utilização de inseminação artificial a partir de 2013. Enfim, a população atingia o número mínimo para sua estabilização. Faltava somente a reprodução ocorrer periodicamente em solo brasileiro. Todo o plantel do Nest foi, então, transferido para a Fazenda Cachoeira, em Minas Gerais, em 2016. A Fazenda Cachoeira, por sua vez, começou a produção de filhotes em 2019, conseguindo dobrar seu plantel inicial em um ano (Purchase, 2019).

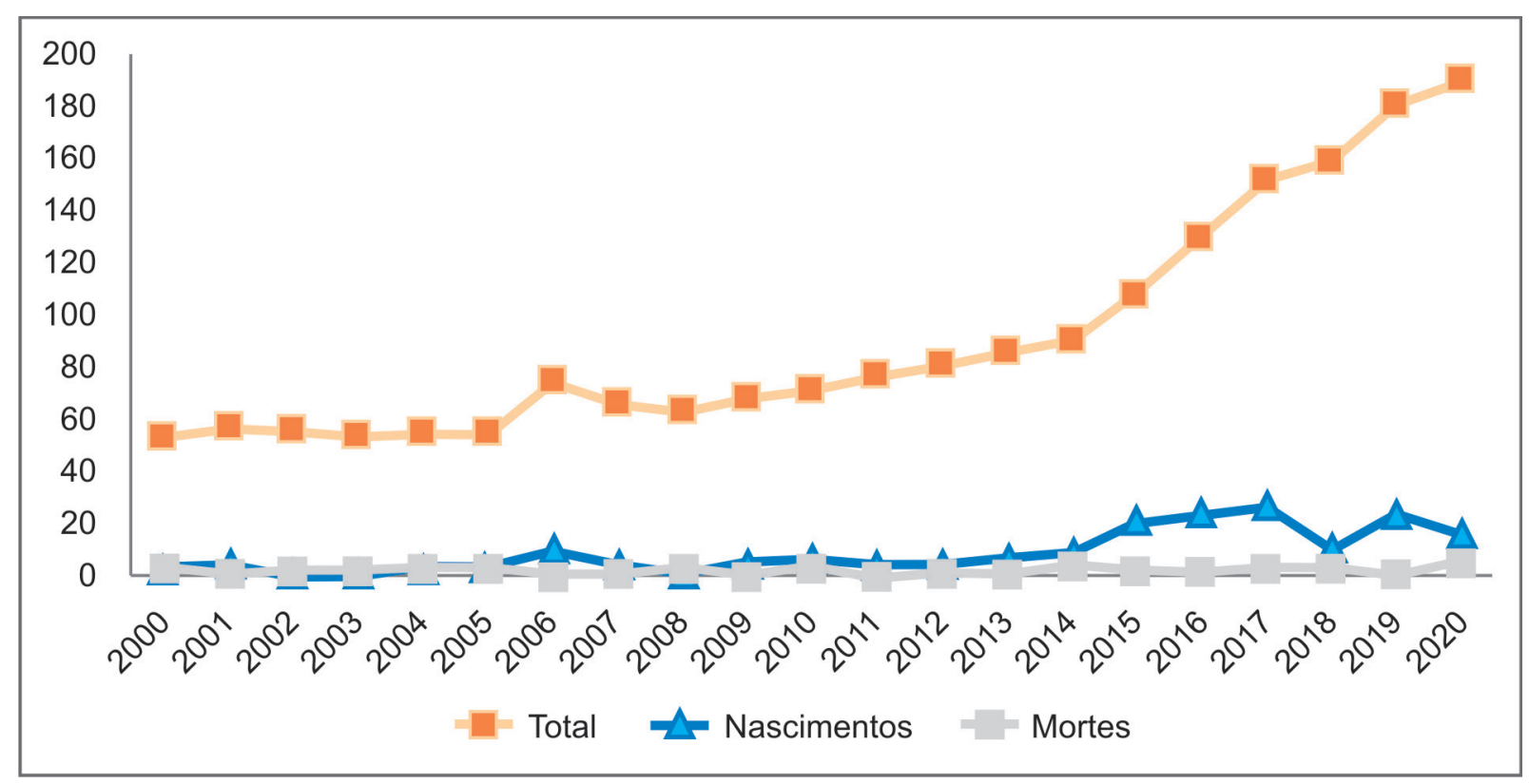

Figura 1 - Número total de indivíduos incluídos no Livro Genealógico da Ararinha-azul, número de nascimentos e mortes por ano, de 2000 a julho de 2020. Fonte: Purchase, 2019. 
Depois da morte do Sheikh Saoud bin Mohammed bin Ali Al-Thani, a AWWP mudou escopo de atuação, fechando o Lubara breeding facility em 2018. De março a maio desse ano todo o plantel da AWWP foi emprestado para manejo da ACTP. Assim, 75\% do plantel de ararinhasazuis do programa ficou em uma localidade. Consequentemente, na temporada de 2018 somente 11 ararinhas-azuis foram produzidas (Figura 1). A temporada de 2019 também foi afetada na ACTP, a qual produziu somente 12 filhotes, incluindo as ninhadas de dois novos pares, além de dois mais antigos. Essa defasagem foi suprida pelo nascimento de 11 filhotes na Fazenda Cachoeira, totalizando 23 filhotes produzidos em 2019. Por motivos de biossegurança a população cativa localizada na ACTP foi dividida em 2019, sendo que 17 aves foram enviadas para o Pairi Daiza zoo, como fruto de Memorando de Entendimento com Pairi Daiza, ACTP, Ministério do Meio Ambiente (MMA) e ICMBio assinado em 2018.

Em 2020, 52 aves foram enviadas da ACTP para o Centro de Reprodução e Reintrodução da Ararinha-azul na Caatinga, construído em uma área de 45ha da Fazenda Ararinha-azul adquirida pela Eco conservation-ACTP, localizada no interior do RVS da Ararinha Azul. Essa população será utilizada para iniciar a reprodução na área de ocorrência da espécie e possibilitar a adaptação e sincronia no ciclo de reprodução, necessárias para o restabelecimento da população em vida livre.

De acordo com Purchase (2019), o plano reprodutivo para a espécie requer pelo menos 25 pares formados. Atualmente, temos 28 pares na ACTP, 12 no Centro de Reprodução de Curaçá, sete no Pairi Daiza e cinco na Fazenda Cachoeira. Entretanto, grande parte dos pares é recémformada ou compreende indivíduos novos, com possibilidade de reprodução reduzida. Apesar do número de novos casais, a população cativa apresenta contínuo crescimento.

Em dezembro de 2019 haviam 180 animais, e até julho de 2020 foram registrados 188 indivíduos (Figura 1, Tabela 1). Em julho de 2020, o programa de cativeiro abrangia cinco mantenedores no mundo: 102 indivíduos na ACTP, na Alemanha; 16 no Pairi Daiza zoo, na Bélgica, 2 no Jurong Bird Park, em Singapura, 51 no Centro de Reprodução da Ararinha-azul em Curaçá e 17 na Fazenda Cachoeira, no Brasil.
Até julho de 2020 a estação reprodutiva da Fazenda Cachoeira não havia terminado com a produção de sete filhotes e havia finalizado na ACTP, com aproximadamente 20 filhotes produzidos. Aguardamos os resultados dos novos pareamentos para as próximas estações reprodutivas. Quanto aos fundadores, ainda restam dois coletados da natureza antes de 1987, os quais não se reproduzem mais, e o restante da população atingiu mais do que a terceira geração.

Como estratégia para sensibilização $e$ captação de recursos foram estabelecidas parcerias com instituições mantenedoras denominadas de "embaixadores da ararinha", que podem expor aves excedentes, provenientes de casais sobre representados. Em novembro de 2017, o Jurong Bird Park começou a exposição de ararinhas-azuis e em 2018, o Pairi Daiza zoo.

Para fortalecer o arranjo institucional para a reintrodução da espécie, foram firmados entre o ICMBio, o MMA, a ACTP e outros parceiros dois Memorandos de Entendimento, em 2016 e 2018. Apesar destes documentos não terem caráter vinculante, registram os compromissos assumidos pelas partes para a reintrodução da espécie com medidas para a recuperação do habitat, engajamento da comunidade, criação $e$ implementação das UCs e o estabelecimento de um Centro de Reintrodução e Reprodução em Curaçá. No primeiro, os mantenedores da espécie se comprometeram a transferir $70 \%$ dos filhotes para o Centro de Reintrodução em Curaçá, promover a captação de recursos $e$ apoiar a construção $e$ funcionamento do centro de reprodução em Curaçá. O segundo Memorando de Entendimento registrou os compromissos de um novo parceiro, o Pairi Daiza zoo/Foundation, da Bélgica, que também apoia a construção e o funcionamento do Centro de Reprodução e Reintrodução em Curaçá. Além disso, se comprometeu a transferir futuros filhotes para o Brasil e apoiar a reintrodução da ararinha-azul com recursos financeiros.

Ainda, conforme previsto nesses Memorandos de Entendimento, em 2019, foi firmado o Acordo de Cooperação n 08/2019 entre a ACTP e o ICMBio, que tem como objeto a "cooperação mútua para a realização de ações voltadas à reintrodução da ararinha-azul no seu ambiente natural, com vigência de 5 anos". 
Tabela 1 - Evolução da população constante no Livro Genealógico da Ararinha-azul de janeiro de 1989 a julho de 2020.

\begin{tabular}{|c|c|c|c|c|c|}
\hline Mantenedor & jan 1989 & set 2001 & jan 2006 & dez 2010 & jul 2020 \\
\hline Al Wabra Wildlife Preservation - AWWP, Catar & 0 & 4 & 43 & 54 & 0 \\
\hline Arco Íris, Brasil & 1 & 0 & 0 & 0 & 0 \\
\hline Association for the Conservation of Threatened - ACTP, Alemanha & 0 & 0 & 13 & 5 & 102 \\
\hline Birds International Incorporated - BII, Filipinas & 3 & 29 & 0 & 0 & 0 \\
\hline Centro de Reprodução e Reintrodução na Caatinga, Curaçá, Bahia, Brasil & 0 & 0 & 0 & 0 & 51 \\
\hline Chaparral, Pernambuco, Brasil & 1 & 3 & 0 & 0 & 0 \\
\hline Fazenda Cachoeira, Minas Gerais, Brasil & 0 & 0 & 0 & 0 & 17 \\
\hline Fundação Lymington, São Paulo, Brasil & 0 & 0 & 2 & 1 & 0 \\
\hline Fundação Parque Zoológico de São Paulo - FPZSP, São Paulo, Brasil & 4 & 2 & 5 & 4 & 0 \\
\hline H. Aviaries, Suíça & 2 & 0 & 0 & 0 & 0 \\
\hline Josef Hämmerli, Suíça & 0 & 18 & 0 & 0 & 0 \\
\hline Jurong Bird Park, Singapura & 0 & 0 & 0 & 0 & 2 \\
\hline Loro Parque, Tenerife, Espanha & 2 & 3 & 5 & 9 & 0 \\
\hline Pairi Daiza zoo, Bélgica & 0 & 0 & 0 & 0 & 16 \\
\hline Vogelpark Walsrode, Alemanha & 1 & 0 & 0 & 0 & 0 \\
\hline Total & 14 & 59 & 68 & 73 & 188 \\
\hline
\end{tabular}

Fonte: Schischakin (2003), Soye \& Barros (2007), Watson (2011), Purchase (2019) e informações recebidas dos mantenedores.

\section{Desafios e conquistas no manejo ex situ}

Ao longo dos anos as instituições envolvidas na formatação inicial do Programa de Cativeiro (e das denominações anteriormente dadas ao manejo ex situ para a conservação) foram mudando, entretanto, se sabe que a população cativa existente é descendente de sete fundadores (Barros et al., 2012; Purchase, 2019), que se acredita que vêm de apenas dois ninhos selvagens, que existiram após 1982 (pares originalmente de propriedade da BII e FLP, e um macho no Criadouro Chaparral).

O nível extremamente baixo de heterozigose na população cativa (Caparroz et al., 2001; Presti et al., 2011), como resultado da consanguinidade e sobre representação de uma linhagem (os fundadores de número 11 e 12 de acordo com Purchase, 2019) foi um grande desafio na década passada. Os índices de similaridade dos indivíduos eram próximos aos observados entre irmãos em outras espécies de aves, evidenciando sua raridade histórica no ambiente selvagem (Caparroz et al., 2001).
Essa pequena população e baixa variabilidade genética levou a pares não produtivos, viés sexual, infertilidade, baixo desenvolvimento de embriões, maturação tardia, mortalidade embrionária e deformidades de filhotes (Watson et al., 2007). De acordo com Hammer \& Watson (2012), entre 2003 e 2010, mais de 140 ovos foram postos a partir de pares constituídos por aves pelo menos na segunda geração, mas apenas três filhotes foram produzidos. Embora a produção de ovos fosse alta em 2010, aproximadamente 50\% dos ovos postos na AWWP eram realmente férteis, mas apenas em torno $10 \%$ do número total de ovos postos eram viáveis. Dos nove pares com ovoposição em 2010 , sete tinham pelo menos um ovo fértil e quatro pares tinham $100 \%$ de fertilidade, mas apenas dois pares produziram filhotes. Por último, dos 40 ovos não desenvolvidos analisados, 18 mostraram morte embrionária precoce e três dos 22 ovos inférteis continham espermatozoides.

Para minimizar os efeitos do endocruzamento nas ararinhas-azuis e aumentar a compatibilidade genética dos casais para 
maximizar a produção reprodutiva, os resultados do mapeamento de microssatélites de cada indivíduo foram usados para os pareamentos, por meio do valor de índice de relação (índice-r). Quanto menor o valor, menos semelhantes geneticamente são as aves. Foi desenvolvido, então, um programa para analisar e apresentar os dados de compatibilidade de pares por meio do Valor de Similaridade Genética (GSV), que é a soma de todos os seus valores de índice-r para orientar os melhores pareamentos (Hammer \& Watson, 2012).

Se por um lado, a população pequena proporciona endocruzamento, por outro, pode haver menos efeitos da depressão por consanguinidade, pois a população selvagem já deve ter experimentado consanguinidade por várias gerações (Templeton \& Read, 1983). Portanto, são mais facilmente reversíveis. O gerenciamento da variabilidade genética da população para evitar a perda alelos adicionais, proporcionando a contribuição equitativa de fundadores seria a melhor solução para preservar essa variabilidade, seguindo Haig \& Avise (1996). $\mathrm{O}$ que nem sempre pôde ser obtido para a ararinha-azul, pela divisão histórica da população e conflitos que atrapalharam o desenvolvimento do manejo (Schischakin, 2003).

Além disso, os problemas de saúde comprometeram as chances de pareamento e para controlar a transmissão de doenças, a incubação de ovos e a criação artificial de filhotes foram realizadas em toda a população (Watson et al., 2007), a qual, por sua vez, possibilita a habituação com o ser humano, o que não é desejável para animais que serão preparados para a soltura.

Como consequência da formação de um plantel grande com aves de diversas fontes, uma alta prevalência de doenças foi inicialmente encontrada na população AWWP, constituindo uma grande variedade de patógenos encontrados comumente em psitacídeos. Na tentativa de combater a alta incidência de doenças, a AWWP investiu em um extenso programa de gerenciamento de saúde (Foldenauer et al., 2007) incorporado no Protocolo de cativeiro da espécie.

Várias aves provenientes da Suíça $e$ Filipinas foram expostas à Doença da Dilatação Proventricular (PDD), uma doença viral crônica que compromete o sistema nervoso, sem tratamento e fatal, além de poliomavírus aviário
(APV), paramixovírus aviário (APMV), herpes vírus aviário (AHV), Chlamydia psittaci (clamídia aviária) e Pseudomonas aeruginosa (Watson et al., 2007, Hammer \& Watson, 2012). A PDD foi responsável por 10 das 16 mortes de ararinha-azul até 2011 na AWWP (Hammer \& Watson, 2012).

Além disso, a endoscopia revelou que as ararinhas possuíam uma fisiologia incomum dos sacos aéreos (estruturas ligadas aos pulmões das aves), com paredes aparecendo em locais aleatórios e, ocasionalmente, desaparecendo em alguns indivíduos, além de opacidade de sacos aéreos e antracose pulmonar, cuja probabilidade era maior em aves mais velhas. A poluição do ar em torno de Manila, onde o BII estava localizado, também afetou a população, demonstrada externamente na coloração da íris da população das Filipinas. Entretanto, outros efeitos do acúmulo de metais pesados não foram mensurados (Watson et al., 2007). Outros problemas veterinários incluíram hepatopatia, insuficiência renal, obesidade, arrancamento de penas, epilepsia e problemas mentais, o que comprometia o potencial reprodutivo da população (Hammer \& Watson, 2012).

Apesar de todos esses entraves, usando análise hormonal, pesquisa da dieta, análise de ovos, sequenciamento de genoma, estimativas de similaridade genética, análise comportamental, um programa veterinário robusto, bem como coleta de sêmen e inseminação artificial, a AWWP foi capaz de estabilizar a população e melhorar o formato da pirâmide populacional. A pirâmide demográfica consiste num histograma que mostra a distribuição de diferentes grupos etários numa população, demonstrando a quantidade de nascimentos por sexo, sobrevivência e expectativa de vida. Posteriormente, a técnica invasiva de inseminação artificial, que pode inclusive criar problemas comportamentais, foi interrompida, $e$ começou a se produzir filhotes criados pelos pais, na AWWP, ACTP e no Brasil (Purchase, 2019).

Uma característica interessante revertida nas décadas passadas foi a maturação muito tardia, com aves com oito anos começando a se reproduzir e com ovipostura de ovos férteis somente a partir de 10 anos, com idade média na primeira cria aos 12 anos (Watson et al., 2007). Atualmente, os casais começam a produzir ovos aos três ou quatro anos de idade, com nascimento de filhotes entre quatro e cinco anos. 
Outro desafio foi o viés sexual feminino na população cativa de ararinha-azul, que é frequente em pequenas populações geneticamente similares. No entanto, entre 2012-2017, a prole foi produzida na proporção de 50:50 (32 machos e 32 fêmeas) em comparação com a proporção de 35:65 (6 machos e 17 fêmeas) nos 6 anos anteriores. Esta é uma reviravolta notável de eventos e essa proporção de 50:50 entre os jovens, combinada com o maior número produzido, deve melhorar muito a pirâmide populacional nos próximos anos (Purchase, 2019).

\section{Discussão}

O manejo ex situ da ararinha-azul sempre foi motivo de muita discussão e polêmica, pois envolve uma espécie rara e que desperta os mais profundos sentimentos no homem pela sua beleza, delicadeza e raridade. Além disso, possui um longo histórico de conflitos entre mantenedores $e$ dificuldades intrínsecas na formação de casais, transferências e produção de filhotes. Parafraseando Watson et al. (2007), gerenciar o manejo ex situ da ararinha-azul tem sido uma experiência desafiadora, às vezes frustrante ao longo dos anos, mas recompensadora.

A primeira polêmica dizia respeito à propriedade das aves e movimentação do plantel. $\mathrm{Na}$ década de 90 havia um dissenso sobre a retirada das aves de mantenedores $e$ encaminhamento para o Brasil. Dissenso esse que era impulsionado pela crença que as aves foram retiradas ilegalmente do Brasil. Entretanto, a Lei de Proteção à Fauna começou a vigorar somente em 1967 (Brasil, 1967) e muitas exportações foram realizadas antes da CITES, a qual foi ratificada pelo Brasil e Suíça em 1975, e posteriormente por outros países, como Filipinas (em 1981), Espanha (em 1986) e Catar (em 2001), que possuíam mantenedores de ararinhas-azuis (Schischakin, 2003; Soye \& Barros, 2007).

Além disso, os primeiros mantenedores privados e zoológicos que se dispuseram a trabalhar em prol da conservação da espécie podem não ser os mesmos responsáveis pela sua retirada da natureza. Todos os proprietários de aves que concordaram em participar da conservação não o fizeram pela anistia do IBAMA. Ao invés disso, assinaram acordos de cooperação com o governo brasileiro. De Dios assumiu um compromisso importante e historicamente significativo em 1991, oferecendo uma ararinhaazul para parear com o último macho selvagem. Naquela época, mais importante do que estabelecer aquele par nativo, era provar que a estratégia estabelecida inicialmente e adotada pelo IBAMA, de colaboração com os proprietários privados e não o confronto, estava funcionando. Essa parceria pública-privada foi considerada um modelo internacional para propiciar a conservação de uma espécie ameaçada (Schinschanin, 1999).

Em 2002, porém, as autoridades brasileiras exigiram o retorno da propriedade de todas as ararinhas-azuis para o Brasil como um prérequisito para a participação no programa de conservação e isso levou ao colapso do CPRAA, que teve tanto sucesso desde a sua formação em 1990 (Schinschanin, 2003).

Esses fatores foram levados em conta quando se instituiu o novo Programa de Cativeiro (ICMBio, 2013). Extinta na natureza, para obter sucesso no PAN, se deveria desenvolver um novo modelo de parceria público-privada, no qual a recuperação da espécie fosse um fator determinante para os participantes e não uma maneira de controle e dominação. Somente por iniciativas dos próprios mantenedores particulares é que a maior parte dos problemas enfrentados nas décadas anteriores do manejo ex situ da ararinhaazul foram abordados e resolvidos (Hammer \& Watson, 2012; Purchase, 2019).

Portanto, o papel do governo brasileiro seria de motivador e organizador, entretanto, a primeira reunião realizada em maio de 2012, no ICMBio, em Brasília, com a participação de representantes de mantenedores não obteve sucesso. $\mathrm{O}$ sucesso dependeu de uma articulação coordenada pelo ICMBio ao longo dos anos posteriores. Houve um esforço extremo para estabelecer os pares recomendados pelo Consultor de Manejo e Genealógico e um novo mantenedor brasileiro. Da mesma forma, a maioria dos problemas de saúde foi eliminada e a tecnologia foi utilizada em favor da reprodução. Atualmente, a população tem um grande número de jovens férteis (Purchase, 2019). Algumas das aves velhas, inférteis ou fisicamente comprometidas não estão incluídas na população reprodutiva e estão disponíveis para o programa de divulgação.

Considerando que a probabilidade de extinção de uma espécie aumenta enormemente quando a população é pequena (Lande, 1988; 
Ballou et al., 1995), é necessário estabelecer um número mínimo viável de indivíduos para a sobrevivência da espécie em longo prazo (Valladares-Padua et al., 2012). Para a ararinhaazul, os modelos construídos com base em Ballou et al. (2011), mostravam que 150 indivíduos deveriam ser obtidos para possibilitar a estabilização da população em cativeiro (Soye \& Barros, 2007; Barros et al., 2012); número este conseguido a partir de 2017.

Em 2012, quando o PAN ararinha-azul foi publicado, havia 79 indivíduos no Programa de Cativeiro (Barros et al., 2012). Em 2017, finalmente, a população cativa alcançou a estabilidade com 152 indivíduos. A estabilidade produzida nos últimos anos conduziu à melhor proporção sexual, melhoria na pirâmide populacional e diminuição na maturação de indivíduos. Todo o esforço de reprodução em cativeiro tem um objetivo único, a reintrodução da ave de volta à Caatinga, conforme estabelecido no plano de ação da espécie (ICMBio, 2019).

Em 2020, 52 ararinhas-azuis foram repatriadas e estão em um centro de reprodução e reintrodução no interior do Refúgio de Vida Silvestre da Ararinha Azul. O Brasil contava em julho de 2020 com 68 espécimes ou 36,2\% da população incluída no Livro Genealógico da espécie. Aproximadamente 20 ararinhas-azuis, candidatas à reintrodução estão em adaptação para o início da reintrodução e restabelecimento da população na área de distribuição histórica.

Deve-se reconhecer as limitações dessa população pequena, que está sujeita a fatores intrínsecos como a perda de genes, que já foi verificada para a espécie (Monteiro \& Miyaki, 2013), além de fatores extrínsecos (estocásticos). A população em cativeiro deverá servir como base para a reconstrução da população na natureza, entretanto, deve se considerar que a ararinhaazul tem aproximadamente $75 \%$ de variabilidade (Purchase, 2019). Além disso, a espécie já sofreu mudanças comportamentais em cativeiro, que podem comprometer a sobrevivência em vida livre e todos estes aspectos devem ser considerados no risco das ações de reintrodução da espécie (IUCN/SSC, 2013).

Portanto, a estratégia de conservação da espécie com manejo populacional ex situ, deverá considerar a população em cativeiro como população núcleo permitindo um fluxo gênico com a população em vida livre, quando ela existir. Isso posto, o manejo ex situ continua sendo o carro-chefe do PAN Ararinha-azul, mas está intimamente integrado com o planejamento da conservação in situ para garantir o melhor efeito possível (ICMBio, 2019). O objetivo da conservação ex situ da ararinha-azul é manejar a população nos mais altos padrões, utilizando os últimos avanços em manejo e reprodução para aumentar a população o mais rápido possível, mantendo ao mesmo tempo a diversidade genética tão saudável quanto possível. Reproduzir o maior número possível de aves, especialmente de aves com alta importância genética e produzir filhotes em excesso para a reintrodução é a prioridade para os próximos anos. As metas, objetivos e ações ex situ são avaliadas periodicamente, considerando os papéis que o manejo pode desempenhar, as características e dimensões que ele deve assumir e quais fatores impedirão ou contribuirão para o sucesso da conservação.

De forma integrada ao manejo ex situ, as ações relacionadas à conservação do habitat são extremamente importantes, especialmente para essa espécie, visto que a degradação do habitat teve um papel importante para o seu declínio (Roth, 1990a, 1990b; Juniper \& Yamashita, 1990, 1991). Sabe-se que mais de $70 \%$ das espécies de psitacídeos é dependente de ambientes florestados, devido aos seus hábitos de forrageamento, descanso e reprodução (Snyder et al., 2000; White et al., 2005), sendo fortemente afetados por diferentes tipos de atividades antrópicas, que reduzem os seus locais de nidificação (Newton, 1994). Neste contexto de perda de habitat e conflitos no uso do solo, as UCs desempenham um papel crucial na manutenção da biodiversidade (Pollock et al., 2017) e as UCs criadas em 2018 garantirão a recuperação e conservação do habitat. Elas também aumentam a representatividade de psitacídeos em UCs, afinal, além da ararinhaazul, mais cinco espécies de psitacídeos ocorrem na região (Mazar Barnett et al., 2014). Por último, a instituição das UCs marca o passo inicial do envolvimento comunitário nas boas práticas para a conservação.

Roth (1990a, 1990b) e Juniper \& Yamashita (1990) listaram, dentre os principais impactos sobre a espécie, a captura, a caça e a sobreposição de nicho com abelhas africanizadas (Apis mellifera). As ações de conservação que perpassam pela fiscalização, educação para a sustentabilidade $e$ 
manejo do habitat são especialmente importantes e devem ser prioridade na gestão das UCs criadas. As medidas de conservação e recuperação do habitat, que inclui a Mata Ciliar com predominância de caraibeira (Tabebuia aurea), devem ser imperativas. Para tanto, boas práticas produtivas, que envolvam a caprino, ovino e bovinocultura, manejo de pastagens e cercamento de riachos efêmeros auxiliarão o aumento do recrutamento de plântulas. Medidas de manutenção da viabilidade hídrica por meio de medidas protetivas das nascentes e cursos d'água, como proposto no início das discussões para a conservação da espécie há 30 anos (Juniper \& Yamashita, 1990) não foram sistematicamente aplicadas. Essas medidas poderão ser obtidas a partir da implementação das UCs, se for considerada uma abordagem incluindo os aspetos sociais, educacionais $e$ culturais, iniciada na região pelo biólogo Marcos Aurélio Da-Ré (Schischakin, 2003).

\section{Conclusão}

A população ex situ da ararinha-azul atingiu um crescimento considerável, a maior parte dos problemas enfrentados foi abordada e, na maioria dos casos, resolvida nos últimos anos. Atualmente, a população tem um grande número de jovens férteis e novos pares. Algumas das aves velhas, inférteis ou fisicamente comprometidas não estão incluídas na população reprodutiva e estão disponíveis para o programa de divulgação.

Quando usada estrategicamente, a conservação ex situ pode ser uma ferramenta potente de conservação para as espécies. Para isso, é necessário estabelecer um equilíbrio entre as partes interessadas com a certeza de que o impacto positivo esperado na conservação dessa espécie supera os riscos potenciais ou qualquer impacto negativo para a espécie, habitat ou ecossistema.

A abordagem por meio do PAN é um modelo de trabalho de como os benefícios da colaboração em conservação podem ser plenamente realizados e essa abordagem integrada mobiliza um conjunto de habilidades e recursos disponíveis para a espécie.

Dentro dessa abordagem, duas UCs na área de ocorrência histórica da espécie foram criadas para propiciar a recuperação da espécie no ambiente natural, onde foi instituído o Centro de Reprodução e Reintrodução da Ararinha-azul, para possibilitar a reintrodução $e$ a produção de filhotes necessários para manter o plantel em cativeiro e a formação dos grupos para as solturas. Estamos mais perto da realização das primeiras reintroduções, procurando manter uma boa relação $e$ articulação com os mantenedores envolvidos e demonstrando que a parceria públicoprivada pode ser responsável pela recuperação de uma espécie extinta na natureza.

A ararinha-azul mobiliza uma legião de fãs $e$ seguidores $e$ as iniciativas de conservação desta espécie bandeira podem proporcionar a recuperação de uma área de Caatinga, historicamente degradada e a melhoria das condições de vida da população residente.

\section{Agradecimentos}

Agradecemos a todas as instituições colaboradoras do PAN Ararinha-azul, especialmente aos mantenedores que forneceram as informações que alimentaram este artigo. Agradecemos Marcos Da-Ré, Yara de Melo Barros, Maria Iolita Bampi, Onildo Marini-Filho e Cristina Yumi Miyaki e todas as pessoas que estiveram envolvidos ao longo destes 30 anos na conservação da espécie.

\section{Referências}

Ballou JD, Gilpin M \& Foose TJ. 1995. Population Management for Survival and Recovery. Columbia University Press. 375p.

Ballou JD, Lacy RC \& Pollak JP. PMx: software for demographic and genetic analysis and management of pedigreed populations (version 1.0). Methods in Ecology and Evolution 3(2): 433-437, 2011.

Barros YM, Soye Y, Miyaki CY, Watson R, Crosta RL \& Lugarini C. 2012. Plano de ação nacional para a conservação da ararinha-azul: Cyanopsitta spixii. Brasília: Instituto Chico Mendes de Conservação da Biodiversidade. 145p.

Berkunsky I et al. Current threats faced by Neotropical parrot populations. Biological Conservation 214:278287, 2017.

Billerman SM, Keeney BK, Rodewald PG \& Schulenberg TS (eds). 2020. Birds of the World. Cornell Lab of Ornithology. < https://birdsoftheworld.org > Acesso em: 07/08/2020. 
BirdLife International. 2016. Anodorhynchus hyacinthinus. The IUCN Red List of Threatened Species 2016. <https://dx.doi.org/10.2305/IUCN.UK.2016-3. RLTS.T22685516A93077457.en.> Acesso em: 03/08/2020.

BirdLife International. 2018. Mitu mitu. The IUCN Red List of Threatened Species 2018. <https://dx.doi.org/10.2305/IUCN.UK.2018-2. RLTS.T22678486A132315266.en.> Acesso em: 31/07/2020.

BirdLife International. 2019a. Anodorhynchus leari. The IUCN Red List of Threatened Species 2019. $<$ https://dx.doi.org/10.2305/IUCN.UK.2019-3.RLTS. T22685521A141364064.en. > Acesso em: 03/08/2020.

BirdLife International. 2019b. Cyanopsitta spixii. The IUCN Red List of Threatened Species 2019. <https://dx.doi.org/10.2305/IUCN.UK.2019-3.RLTS. T22685533A153022606.en. > Acesso em: 31/07/2020.

Brasil. 1967. Lei $\mathrm{n}^{\circ}$ 5.197, de 3 de janeiro de 1967. Dispõe sobre a proteção à fauna e dá outras providências. Diário Oficial da União de: 05/01/1967. <http://www.planalto.gov.br/ccivil_03/leis/L5197.

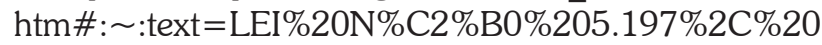
DE \% $203 \% 20$ DE\% 20JANEIRO \% 20DE\% 20 1967\&text $=$ Disp\%C3\%B5e\%20sobre\%20a\%20 prote\%C3\%A7\%C3\%A3०\%20\%C3\%A0,1\%C2\%BA.> Acesso em: 03/08/2020.

Brasil. 2018. Decreto $n^{\circ} 9.406$, de 5 de junho de 2018. Cria o Refúgio de Vida Silvestre da Ararinha Azul e a Área de Proteção Ambiental da Ararinha Azul. Diário Oficial da União de: 06/06/2018 < https://www. in.gov.br/materia/-/asset_publisher/Kujrw0TZC2Mb/ content/id/17538364/do1-2018-06-06-decreto-n-9402-de-5-de-junho-de-2018-17538330> Acesso em: 04/08/2020.

Brettas EP \& Silveira LF. 2015. Terra papagalli. Marte, 373p.

Butchart SHM, Stattersfield AJ \& Collar NJ. How many Bird extinctions have we prevented? Oryx 40: 266-278, 2006.

Butchart SHM, Lowe S, Martin RW, Symes A, Westrip JRS \& Wheatley $\mathrm{H}$. Which bird species have gone extinct? A novel quantitative classification approach, Biological Conservation 227: 9-18, 2018.

Caparroz R, Miyaki C, Bampi MI \& Wajntal A. Analysis of the genetic variability in a sample of the remaining group of Spix's Macaw (Cyanopsitta spixii, Psittaciformes: aves) by DNA fingerprinting. Biological Conservation 99: 307-311, 2001.

FoldenauerU, etal. Hematologic and plasmabiochemical values of Spix's Macaws (Cyanopsitta spixii). Journal of Avian Medicine and Surgery 21: 275-282, 2007.
Fleishman E, Murphy DD \& Brussard PF. A new method for selection of umbrella species for conservation planning. Ecological Applications 10(2): 569-579, 2000.

Forshaw JM. 2010. Parrots of the world. Princeton University Press. 336p.

Haig SM \& Avise JC. 1996. Avian conservation genetics, p. 160-189. In: Avise JC \& Hamrick JL (eds.). Conservation Genetics - Case Histories from Nature. Chapman and Hall. 512p.

Hammer S \& Watson R. The challenge of managing Spix Macaws (Cyanopsitta spixii) at Qatar - an elevenyear retrospection. Der Zoologische Garten 81: 81-95, 2012.

IBAMA (Instituto Brasileiro de Meio Ambiente e Recursos Naturais Renováveis). Em caráter extremamente excepcional, não confiscar exemplares de ararinha azul que estejam submetidas ao Plano de Manejo estabelecido pelo Comitê C. Spixii. Diário Oficial da União de: 30/10/1990 <http://extwprlegs1.fao.org/ docs/pdf/bra12852.pdf>. Acesso em: 07/08/2020.

ICMBio (Instituto Chico Mendes de Conservação da Biodiversidade). 2012a. Portaria $\mathrm{n}^{\circ} 17$, de 17 de fevereiro de 2012, que aprova o Plano de Ação Nacional para a Conservação da Ararinha-azul (Cyanopsitta spixii) - PAN Ararinha-azul. Diário Oficial da União de: 22/02/2012, retificada no D.O.U. de: 27/02/2012.

ICMBio. 2012b. Instrução Normativa $\mathrm{n}^{\circ} 22$, de 27 de março de 2012. Estabelece os procedimentos para os Programas de Cativeiro de Espécies Ameaçadas. Diário Oficial da União de: 28/03/2012 <https://www.icmbio. gov.br/portal/images/stories/biodiversidade/faunabrasileira/normativas/IN_Programa_Cativeiro_222012.pdf> Acesso em: 10/08/2020.

ICMBio. 2013. Portaria n ${ }^{\circ} 212$, de 23 de julho de 2013. Aprova o Programa de Cativeiro da Ararinha-azul (Cyanopsitta spixii), espécie ameaçada de extinção, estabelecendo seu objetivo, objetivos específicos, ações estratégicas para a conservação ex situ da espécie. Diário Oficial da União de: 24/07/2013 <https://www. icmbio.gov.br/portal/images/stories/biodiversidade/ fauna-brasileira/programas-cativeiro/ararinha_azul/ Portaria_n_212.pdf > Acesso em: 04/08/2020.

ICMBio. 2016a. Portaria $n^{\circ} 80$, de 8 de agosto de 2016. Atualiza e aprova o Plano de Ação Nacional para a Conservação da Ararinha-azul (Cyanopsitta spixii), - PAN Ararinha-azul, táxon ameaçado de extinção, estabelecendo seu objetivo geral, objetivos específicos, prazo de execução, abrangência e formas de implementação e supervisão e revoga a Portaria ICMBio $\mathrm{N}^{\circ}$ 17, de 17 de fevereiro de 2012. Diário Oficial da União de: 11/08/2016 < http://www.haidar. com.br/arquivos/2016/port\%20348.pdf> Acesso em: 10/08/2020. 
ICMBio. 2019. Portaria $n^{\circ} 353$, de 25 de julho de 2019. Aprova $2^{\circ}$ ciclo do Plano de Ação Nacional para a Conservação da Ararinha-azul (Cyanopsitta spixii) - PAN Ararinha-azul, contemplando 1 espécie ameaçada de extinção, estabelecendo seu objetivo geral, objetivos especícos, prazo de execução, formas de implementação, supervisão, revisão e institui o Grupo de Assessoramento Técnico (Processo SEI nº. 02061.000869/2017-11). Diário Oficial da União de 30/07/2019<https://www.icmbio.gov.br/portal/ images/stories/docs-pan/pan-ararinha-azul/2-ciclo/panararinha-azul-portaria-aprovacao.pdf $>$ Acesso em: 04/08/2020.

IUCN/SSC (The International Union for Conservation of Nature/Species Survival Commission). 2013. Guidelines for Reintroductions and Other Conservation Translocations. Version 1.0. IUCN Species Survival Commission. 57 p. <https://www.iucn.org/content/ guidelines-reintroductions-and-other-conservationtranslocations > Acesso em: 10/08/2020.

IUCN/SSC. 2014. Guidelines on the Use of Ex Situ Management for Species Conservation. Version 2.0. IUCN Species Survival Commission. <www.iucn.org/ about/work/programmes/species/publications/iucn_ guidelines_and_policy_statements/ $>$ Acesso em: 30/07/2020.

Juniper A. 2002. Spix's Macaw: the race to save the world's rarest bird. Washington Square Press, 293p.

Juniper T \& Yamashita C. The conservation of Spix's macaw. Oryx 24: 224-228, 1990.

Juniper AT \& Yamashita C. The habitat and status of Spix's Macaw Cyanopsitta spixii. Bird Conservation International 1: 1-9, 1991.

King WB. 1978. Endangered Birds of the World: The ICBP Bird Red Data Book. ICBP/IUCN. 800p.

LPF (Loro Parque Foundation). The Spix's Macaw start to breed. Cyanopsitta 53/54: 12-15, 1999.

Lande R. Genetics and demography in biological conservation. Science 241: 1455-60, 1988.

Lugarini C, Barbosa AEA \& Oliveira KG (orgs.) 2012. Plano de Ação Nacional para a Conservação da Araraazul-de-Lear. 2. ed. ICMBio. 147p.

Mazar Barnett J, Silva CLG, Araujo HFP, Roos AL, Machado CG, Uejima AMK \& Naka LN. The avifauna of Curaçá (Bahia): the last stronghold of Spix's Macaw. Revista Brasileira de Ornitologia 22: 121-137, 2014.

MMA (Ministério do Meio Ambiente) 2014a. Portaria $\mathrm{n}^{\circ} 444$, de 17 de dezembro de 2014. Dispõe sobre a Lista Nacional Oficial de Espécies da Fauna Ameaçada de Extinção. Diário Oficial da União de: 18/12/2014. <https://www.icmbio.gov.br/sisbio/images/stories/ instrucoes_normativas/PORTARIA_N\%C2\%BA_444_
DE_17_DE_DEZEMBRO_DE_2014.pdf > Acesso em: 31/07/2020.

MMA 2014b. Portaria $n^{\circ} 43$, de 31 de janeiro de 2014. Diário Oficial da União de 05/02/2014 < https:// www.mma.gov.br/images/noticias_arquivos/pdf/2014/ Fev_2014/materia_5_2_mma_define_regras_link.pdf > Acesso em: 07/08/2020.

MMA. 2018. Portaria $\mathrm{n}^{\circ} 444$, de 26 de novembro de 2018. Institui a Estratégia Nacional para Conservação de Espécies Ameaçadas de Extinção. Diário Oficial da União Edição de: 28/11/2018 < https://www.in.gov. br/materia/-/asset_publisher/Kujrw0TZC2Mb/content/ id/52249904/do1-2018-11-28-portaria-n-444-de26-de-novembro-de-2018-52249804> Acesso em: 05/08/2020.

Newton I. The role of nest sites in limiting the numbers of hole-nesting birds: A review. Biological Conservation 70: 265-276, 1994.

Monteiro RS \& Miyaki CY. 2013. Relatedness between pairs of the extinct-in-the-wild Spix's macaw (Cyanopsitta spixii), p. 183. In: Resumos do 59 Congresso Brasileiro de Genética.

NPS (National Park Service). 2019. California Condor Chick \#1000 Fledges at Zion National Park < https:// www.nps.gov/zion/learn/news/california-condor-chick1000-fledges-at-zion.htm> Acesso em: 30/10/2020.

Olah $\mathrm{G}$ et al. Ecological and socio-economic factors affecting extinction risk in parrots. Biodiversity and Conservation 25: 205-223, 2016.

Presti FT, Oliveira-Marques AR, Caparroz R, Biondo C \& Miyaki CY. Comparative analysis of microsatellite variability in five macaw species (Psittaciformes, Psittacidae): application for conservation. Genetics and Molecular Biology 34(2): 348-352, 2011.

Pollock LJ, Thuiller Wb \& Jetz W. Large conservation gains possible for global biodiversity facets. Nature 546(7656): 141-144, 2017.

Purchase C. 2019. International Studbook Annual Report 2018 and Recommendations for 2019 Spix's Macaw (Cyanopsitta spixii). 38p.

Roth P. Bericht fiber ein 1985-1988 durchgefuhrtes Projekt. Papageien 90(3): 86-88, 1990a.

Roth P. Bericht fiber ein 1985-1988 durchgefuhrtes Projekt. Papageien 90(4): 121-125, $1990 \mathrm{~b}$.

Safford RJ \& Jones CG. Strategies for Land-Bird Conservation on Mauritius. Conservation Biology 12: 169-176, 1998.

Schischakin N. 1999. The Spix's macaw conservation program: a non-extinction history. The AFA Watchbird nov/dec: 46-55. 
Schischakin N. 2003. The Spix's macaw. Can it survive the politics of conservation? A personal perspective of the efforts to save one of the world's most endangered species and the controversy that surrounds it. 2003 Proceedings of the International Aviculturists Society. $125 \mathrm{p}$.

Snyder N, McGowan P, Gilardi J \& Grajal A. 2000. Parrots: Status survey and conservation action plan 2000-2004. IUCN. 180p.

Soye Y \& Barros YM. 2004. Saving the Spix's macaw Cyanopsitta spixii - a captive management and species recovery handbook. 570p.

Templeton AR \& Read B. 1983. The elimination of inbreeding depression in a captive herd of Speke's gazelle, p. 241-261. In: Schonewald-Cox CM, Chambers SM, MacBryde B \& Thomas L (eds.). Genetics and Conservation: A Reference for Managing Wild Animal and Plant Populations. Benjamin/Cummings. 722p.

Valladares-Padua CB, Martins CS \& Rudran R. 2012. Manejo integrado de espécies ameaçadas, p.633-651.
In: Cullen Jr L et al. (eds). Métodos de Estudo em Biologia da Conservação e Manejo da Vida Silvestre. 2n ed. Ed UFPE. 652p.

Vergara-Tabares DL, Cordier JM, Landi MA, Olah $G$ \& Nori J. Global trends of habitat destruction and consequences for parrot conservation. Global Change Biology 26: 4251-4262, 2020.

Watson R. 2011. International Studbook Annual Report and Recommendations for 2011 Spix's Macaw (Cyanopsitta spixii). 48p.

Watson R, Deb A \& Hammer S. 2007. Managing the World's Largest Population of Spix's Macaws (Cyanopsitta spixii). AFA Annual Convenction 2007 Proceedings <http:/awwp.alwabra.com/wp-content/ uploads/2014/04/SP.61_Managing_Spix.pdf >. Acesso em: 31/07/2020.

White Jr. TH, Collazo JA \& Vilella FJ. Survival of captive- reared Puerto Rican parrots released in the Caribbean National Forest. The Condor 107: 424-432, 2005.

\section{Biodiversidade Brasileira - BioBrasil. \\ Fluxo Contínuo}

$$
\text { n. 3, } 2021
$$

http://www.icmbio.gov.br/revistaeletronica/index.php/BioBR

Biodiversidade Brasileira é uma publicação eletrônica científica do Instituto Chico Mendes de

Conservação da Biodiversidade (ICMBio) que tem como objetivo fomentar a discussão e a disseminação de experiências em conservação e manejo, com foco em unidades de conservação e espécies ameaçadas.

ISSN: 2236-2886 